\title{
Speciation and preconcentration of inorganic antimony in waters by Duolite GT-73 microcolumn and determination by segmented flow injection-hydride generation atomic absorption spectrometry (SFI-HGAAS)
}

\author{
Aslı Erdem, Ahmet E. Eroğlu* \\ Department of Chemistry, Izmir Institute of Technology, 35430 Urla-Izmir, Turkey
}

Received 5 November 2004; received in revised form 1 April 2005; accepted 27 April 2005

Available online 25 May 2005

\begin{abstract}
A selective matrix removal/separation/enrichment method, utilizing a microcolumn of a chelating resin with $-\mathrm{SH}$ functional groups (Duolite GT-73), was proposed for the determination of $\mathrm{Sb}$ (III) in waters by segmented flow injection-hydride generation atomic absorption spectrometry (SFI-HGAAS). The resin was selective to $\mathrm{Sb}$ (III) at almost all $\mathrm{pH}$ and acidity values employed, whereas $\mathrm{Sb}(\mathrm{V})$ was not retained at all and could be determined after a pre-reduction step with L-cysteine. Spike recoveries were tested at various concentration levels in different water types and were found to vary between 85 and $118 \%$. Accuracy of the proposed methodology was checked by analyzing a standard reference material and a good correlation was found between the determined $\left(13.3 \pm 1.1 \mu \mathrm{g} 1^{-1}\right)$ and the certified value $\left(13.79 \pm 0.42 \mu \mathrm{g} 1^{-1}\right)$. The method was applied to several bottled drinking water samples for antimony determination with and without preconcentration and none of the samples were found to contain antimony above the permissible level $\left(5 \mu \mathrm{g} 1^{-1}\right)$. The characteristic concentration (the concentration of the analyte corresponding to an absorbance of 0.0044 ) was $0.55 \mu \mathrm{g} 1^{-1}$ and the $3 \mathrm{~s}$ limit of detection (LOD) based on five times preconcentration was $0.06 \mu \mathrm{gl}^{-1}$. The applicability of the microcolumn separation/preconcentration/matrix removal method for flow injection systems was also demonstrated.
\end{abstract}

(C) 2005 Elsevier B.V. All rights reserved.

Keywords: Antimony; Speciation; Preconcentration; Microcolumn; Duolite GT-73; SFI-HGAAS

\section{Introduction}

The use, importance, bioavailability of antimony and antimony compounds are very well documented in literature $[1,2]$. The increased use of the element and its compounds in many applications makes its determination necessary in environmental, biological, metallurgical, and other industrial samples. A critical review by Nash et al. has focused on the methodologies for the determination of both total and the chemical species of antimony in aqueous and solid environmental samples [3]. The authors have also outlined the sample preparation methods, and both common and uncommon de-

\footnotetext{
* Corresponding author. Tel.: +90 232 7507533; fax: +90 2327507509 .

E-mail address: ahmeteroglu@iyte.edu.tr (A.E. Eroğlu).
}

tection techniques. Another review by Krachler et al. underlined the analytical methods for the speciation of volatile and non-volatile $\mathrm{Sb}$ compounds in biota, putting special emphasis on the hyphenated techniques [4]. Antimony can exist in a variety of oxidation states (-III, 0, III, V), but it is mainly found in two oxidation states (III and V) in environmental samples. These two forms exhibit pronounced differences in their analytical behavior, toxicity and mobility. Trivalent species are reported to be more toxic than pentavalent forms [5]. Antimony and its compounds are considered as pollutants of priority interest by the Environmental Protection Agency of the United States (USEPA) [6] and European Union [7]. The USEPA drinking water standards for maximum contaminant level goal (MCLG) and maximum contaminant level (MCL) are both $6 \mu \mathrm{g}^{-1}$ [8]. The European Union estab- 
lished a maximum admissible concentration of antimony in drinking water of $5 \mu \mathrm{gl}^{-1}$ [9]. Typical concentrations of dissolved antimony in unpolluted waters are less than $1 \mu \mathrm{g} \mathrm{l}^{-1}$ which may necessitate an enrichment step prior to analytical measurement depending on the instrumental detection limit that can be achieved by the available technique. Higher concentrations can be found in the proximity of anthropogenic sources [2]. Ion-exchange [10] and chelating sorbents [11] and co-precipitation [12] can be pronounced as the most commonly used separation and preconcentration methods used in antimony determinations. Of all the methods for the determination of antimony in various samples, inductively coupled plasma mass spectrometry (ICP-MS) [13] and atomic absorption spectrometry (AAS) [14-19], especially after a hydride generation step, are the most useful and the sensitive techniques. Alternative applications using chromatographic [20], fluorimetric [21], and spectroscopic detection [22] systems can also be used.

The purpose of this study is to develop a matrix removal/speciation/enrichment system for the determination of inorganic $\mathrm{Sb}(\mathrm{III})$ and $\mathrm{Sb}(\mathrm{V})$ in waters. For this purpose, a chelating resin with - SH functional groups (Duolite GT-73) was tried and its selectivity towards inorganic $\mathrm{Sb}$ (III) and $\mathrm{Sb}(\mathrm{V})$ was examined (organic Sb species were not tried to be determined in the present work which can be the subject of further studies). The efficiency of the sorbent was studied as a matrix separation/speciation/preconcentration agent and then was tested by analyzing a standard reference material (SRM) and by spike recovery tests. The samples prepared, using the mentioned methodology was analyzed by segmented flow injection hydride generation atomic absorption spectrometry (SFI-HGAAS).

\section{Experimental}

\subsection{Reagents and materials}

Ultra pure water $(18.2 \mathrm{M} \Omega$ ) was used throughout the study. Glassware and plasticware were cleaned by soaking in $10 \%$ $(\mathrm{v} / \mathrm{v})$ nitric acid and rinsed with ultra pure water prior to use. Separate, $1000 \mathrm{mg} \mathrm{l}^{-1}$, stock solutions of $\mathrm{Sb}$ (III) and $\mathrm{Sb}(\mathrm{V})$ were prepared by dissolving potassium antimony tartrate (Sigma-Aldrich, 99\%, product code: P-6949, CAS no [28300-74-5]) and potassium antimonate (Riedel-de Haën, $\geq 99 \%$, product code: 31149 , CAS no: [12208-13-8]), respectively, in ultra pure water. Lower concentration standards were prepared daily from their stock standards. The resin employed was Duolite GT-73, a macroporous resin with a cross-linked polystyrene matrix bearing thiol $(-\mathrm{SH})$ functional groups, (Supelco, product code: 10354, CAS no: [113834-91-6]). Nitric acid (Merck, 65\%, product code: 100456) and hydrochloric acid (Merck, 37\%, product code: 100317) were used in the preparation of the standard solutions and during $\mathrm{pH}$ adjustment. Potassium iodate (Merck, 99.7-100.4\%, product code: 105051 , CAS no: [7758-05-6])

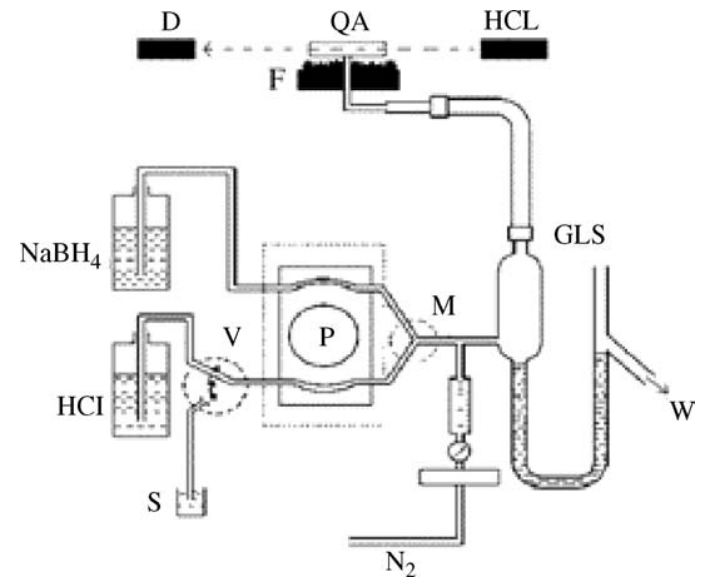

Fig. 1. Segmented flow injection (SFI-HGAAS) system used in this study (taken from Operator's Manual of the instrument). D: detector, QA: quartz tube atomizer, HCL: hollow cathode lamp, F: air-acetylene flame, S: acidified sample, V: injection valve, $\mathrm{P}$ : two-channel peristaltic pump, M: mixing piece, GLS: gas/liquid separator, W: waste.

was used as eluent and L-cysteine (Sigma, $\geq 98 \%$, product code: C-7352, CAS no: [52-90-4]) served as the pre-reducing agent. Potassium hydrogen phthalate (Merck, 99.5\%, product code: 104874, CAS no: [877-24-7]), sodium acetate (Carlo Erba, 99-101\%, product code: 366207, CAS no: [6131-904]), potassium dihydrogen phosphate (Merck, $99.5 \%$, product code: 104873, CAS no: [7778-77-0]) and sodium bicarbonate (Sigma, 99.7-100.3\%, product code: S-6014, CAS no: [144-55-8]) were used in the preparation of buffer solutions. Sodium borohydride (Merck, 96.0\%, product code: 806373 , CAS no: [16940-66-2]) was prepared daily and stabilized by the addition of sodium hydroxide (Merck, 99\%, product code: 106498 , CAS no: [1310-73-2]). Merck reagents were obtained from Darmstadt (Germany); Sigma, Sigma-Aldrich, Riedel-de Haën, and Supelco reagents from Taufkirchen (Germany); and Carlo Erba reagents from Rodano (Italy). PTFE tubings were used in the preparation of microcolumns.

\subsection{Instrumentation and apparatus}

An atomic absorption spectrometer, Thermo Elemental Solaar M6 Series with an air-acetylene burner assembly, was used in all measurements. In sorption studies with batch process, Yellowline RS 10 (Staufen, Germany) reciprocating shaker was used to provide efficient mixing. The manifold for off-line separation/preconcentration system utilized a Gilson Minipuls 3 (Villers le Bel, France) and/or Ismatec 834 (Zürich, Switzerland) model peristaltic pump with either Tygon or PVC tubings of various diameters. The $\mathrm{pH}$ measurements were performed by using Corning 450 $\mathrm{pH} /$ ion meter with a $\mathrm{pH}$ combination electrode. The hydride generation system, coupled with segmented flow injection unit (Thermo Elemental Solaar M6 Series SFI 90, Fig. 1) was used throughout the study. In the SFI 90 system, the standby delay, stabilize delay and baseline delay periods were 
applied as 20, 40 and $40 \mathrm{~s}$, respectively, as recommended by the Operators' Manual. Antimony hollow cathode lamp operated with a maximum current of $10 \mathrm{~mA}$ at $217.6 \mathrm{~nm}$ and deuterium $\left(\mathrm{D}_{2}\right)$ background correction was used in all measurements. Air-acetylene flame was used for heating the quartz tube $(10 \mathrm{~cm} \times 8 \mathrm{~mm}$, i.d. $)$ externally. Krachler et al. [23] have pointed out that the Sb signal strongly depends on the temperature of the quartz tube atomizer; therefore, the air and acetylene flow rates were kept constant in all determinations. Nitrogen was used as the carrier gas.

\subsection{Speciation and preconcentration of $S b(I I I)$ and $\mathrm{Sb}(\mathrm{V})$}

\subsubsection{Initial sorption/elution studies}

The suitability of several sorbents having - $\mathrm{SH}$ functional groups to enrich $\mathrm{Ge}$, Te and $\mathrm{Se}$ has been shown previously [24-26]. Therefore, initial experiments were concentrated on the sorption behavior of various sorbents for the speciation of $\mathrm{Sb}(\mathrm{III})$ and $\mathrm{Sb}(\mathrm{V})$. For this purpose, Muromac and Chelex100 (owing iminodiacetate functional groups) Duolite GT73 (owing mercapto functional groups) and several zeolites, namely Zeolite ZSM-5 and Clinoptilolite were tried. Initial studies gave a rough idea about the uptake of selected sorbents towards $\mathrm{Sb}(\mathrm{III})$ and $\mathrm{Sb}(\mathrm{V})$ species. For this purpose, standard solutions of $40.0 \mu \mathrm{g}^{-1} \mathrm{Sb}$ (III) and $\mathrm{Sb}(\mathrm{V})$ were prepared from their respective stock solutions separately. As a starting point, the $\mathrm{pH}$ of the solutions was adjusted to 7.0. About $0.1 \mathrm{~g}$ sorbent was added and after shaking manually the mixture was placed on the shaker for $15 \mathrm{~min}$. The contents were filtered through filter paper and the filtrate was analyzed for their percent sorption by SFI-HGAAS using the optimum conditions. Among the sorbents investigated, Duolite GT-73 offered significant results for the speciation of antimony at $\mathrm{pH} 7.0$; therefore, the rest of the experiments were conducted with this particular resin. Subsequently, several eluents were tried for the desorption of the previously sorbed $\mathrm{Sb}$ (III) from the resin. For this purpose, $50.0 \mathrm{ml}$ of $40.0 \mu \mathrm{g}{ }^{-1} \mathrm{Sb}$ (III) was prepared and the sorption process was performed with Duolite GT-73, as mentioned above. Following this step, the resin was taken into the eluent and the new mixture was shaken once again for $15 \mathrm{~min}$. Afterwards, the solution was filtered and analyzed by SFI-HGAAS using the optimum conditions. Blank solution was also prepared by the same procedure, by adding the same amount of resin into ultra pure water and eluting it after filtration.

\subsubsection{Microcolumn sorption}

The manifold for off-line flow injection preconcentration utilized a peristaltic pump furnished with either Tygon or PVC tubings of various diameters and a packed microcolumn. Microcolumns were prepared from PTFE tubings and filled with the Duolite GT-73 chelating resin. The size of the resin particles were $125-150 \mu \mathrm{m}$. The microcolumn had $1.5 \mathrm{~mm}$ i.d. and $5 \mathrm{~cm}$ active length. The sorption and elution flowrates were both kept at $1 \mathrm{ml} \mathrm{min}^{-1}$.

\subsubsection{Preconcentration factor}

In order to investigate the efficiency of Duolite GT73 chelating resin for the enrichment of $\mathrm{Sb}$ (III) from different concentrations and different volumes (keeping the absolute amount constant), solutions at various volumes (20.0-200.0 ml) and concentrations (10.0-1.0 $\left.\mu \mathrm{g} \mathrm{l}^{-1}\right)$ were prepared. Meanwhile, the possible effects (interference, suppression, or enhancement) of the matrix of each type of water sample were checked. Appropriate amount of sorbent (0.1-1.0 g, proportionally increased with sample volume) was added into each solution and the same sorption/elution procedure was applied with an eluent volume of $20.0 \mathrm{ml}$. The preconcentration study was also performed with water samples including tap water, sea water and ultra pure water.

\subsection{Method validation and spike recovery experiments}

The efficiency of the proposed method was first checked via spike recovery tests. This was realized by spiking $20.0 \mathrm{ml}$ aliquots of water samples with $20.0 \mu \mathrm{g} 1^{-1} \mathrm{Sb}$ (III) and $\mathrm{Sb}(\mathrm{V})$ separately and applying to the separate microcolumns of Duolite GT-73 resin. After loading the analyte, each microcolumn was washed with ultra pure water and then eluted with $20.0 \mathrm{ml}$ of $0.05 \mathrm{M} \mathrm{KIO}_{3}$ in $2 \mathrm{M} \mathrm{HCl}$. Throughout the study $\mathrm{KIO}_{3}$ was used to elute the sorbed antimony from the resin. Blank solution and the calibration standards $\left(1.0-40.0 \mu \mathrm{g}^{-1}\right)$ were prepared using the same sorption/elution procedure. These standards prepared after sorption/elution process can therefore be considered as the "matrix-matched standards". The concentration of Sb in the eluates was determined by SFI-HGAAS and the percent recovery in each sample was calculated.

In addition to spike recovery experiments, a standard reference material, Trace Elements in Natural Water (NIST, Cat. No. 1640) was also employed for method validation. Ten milliliters aliquots were taken and processed by the proposed methodology; loading onto the Duolite GT-73 microcolumn and elution with $\mathrm{KIO}_{3} / \mathrm{HCl}$ mixture. The eluates were analyzed by SFI-HGAAS and Sb concentrations were determined from the calibration plot obtained with the matrixmatched standards.

\section{Results and discussion}

The first part of the study was concentrated on the optimization of measurement conditions with SFI-HGAAS system since the sensitivity of the method is influenced by several factors, such as the carrier gas flowrate, the concentrations of acid, $\mathrm{NaBH}_{4}$ and pre-reducing agent, etc. The second part was concerned on finding out an appropriate sorbent for the speciation and preconcentration of antimony. The third part was the validation of the method through spike tests and analysis of SRM and the final part was the application of the method to several water samples. 


\subsection{Optimization of the SFI-HGAAS parameters}

Hydride generation methods have been widely used in atomic spectrometry due to their simplicity, high sensitivity, and speciation capability. The technique has also been used in the determination of antimony in environmental samples; sometimes after a suitable preconcentration step, if required [27]. Although the necessary conditions for Sb determination are given in these applications, initial studies in this work were still concentrated on the optimization of the SFIHGAAS parameters, since a different enrichment procedure and different chemicals were used. It is known that only $\mathrm{Sb}$ (III) gives an efficient signal in HGAAS; therefore, the optimizations were carried out with standard $\mathrm{Sb}$ (III) solution. Pre-reduction conditions of $\mathrm{Sb}(\mathrm{V})$ was also optimized.

The first parameter was the acidity of the sample, since generation of the hydride depends upon this parameter. Among various acids, $\mathrm{HCl}$ has been almost universally accepted and, therefore, it was used throughout the study. In order to determine the acid concentration for optimum performance, $5.0 \mu \mathrm{g} \mathrm{l}^{-1} \mathrm{Sb}$ (III) solution was prepared in various concentrations from 0.012 to $2.4 \mathrm{M}$ of hydrochloric acid and analyzed using SFI-HGAAS. The absorbance values are almost constant at $\mathrm{HCl}$ concentrations higher than $0.01 \mathrm{M} \mathrm{HCl}$, and $0.12 \mathrm{M} \mathrm{HCl}$ was chosen as an optimum value. Almost constant response from $\mathrm{HCl}$ concentration up to $2.5 \mathrm{M}$ (and beyond) will permit the use of higher acid concentrations, if needed, without a loss in sensitivity.

The other parameters, such as the percentage of $\mathrm{NaBH}_{4}$ and the carrier gas flow rate were also optimized. The optimum signal was obtained with $1.0 \%(\mathrm{~m} / \mathrm{v}) \mathrm{NaBH}_{4}$ in the aqueous standards so, unless stated otherwise, it was used throughout the study. In addition, the maximum absorbance was obtained at a carrier gas flow rate of $200.0 \mathrm{ml} \mathrm{min}^{-1}$ with SFI-90. With the optimized conditions, the calibration plot for $\mathrm{Sb}$ (III) was linear up to $80.0 \mu \mathrm{g} \mathrm{l}^{-1}$ and the characteristic concentration (the concentration of the analyte corresponding to an absorbance of 0.0044) was $0.55 \mu \mathrm{g}{ }^{-1}$ and the $3 \mathrm{~s} \mathrm{limit}$ of detection was $0.30 \mu \mathrm{gl}^{-1}$ when preconcentration was not employed (Table 1).

Since $\mathrm{Sb}(\mathrm{V})$ cannot be completely reduced to stibine with $\mathrm{NaBH}_{4}$, and so, exhibits a very poor sensitivity compared to $\mathrm{Sb}(\mathrm{III})$, there is a need to pre-reduce $\mathrm{Sb}(\mathrm{V})$ to $\mathrm{Sb}$ (III). Several

Table 1

SFI-HGAAS performance data

\begin{tabular}{ll}
\hline Calibration response curve $^{\mathrm{a}}$ & $y=0.099 x+0.0113, R^{2}=0.9993$ \\
Calibration response curve $^{\mathrm{b}}$ & $y=0.087 x-0.0031, R^{2}=0.9999$ \\
Calibration response curve $^{\mathrm{c}}$ & $y=0.0080 x+0.0030, R^{2}=0.9997$ \\
Limit of detection $^{\mathrm{d}}$ & $0.30 \mu \mathrm{gl}^{-1}$ \\
Characteristic concentration $^{\mathrm{e}}$ & $0.55 \mu \mathrm{g} \mathrm{l}^{-1}$ \\
\hline
\end{tabular}

a $\mathrm{Sb}(\mathrm{III})$ without pre-reduction.

b $\mathrm{Sb}(\mathrm{III})$ in $2.0 \%(\mathrm{~m} / \mathrm{v})$ L-cysteine.

c $\mathrm{Sb}(\mathrm{V})$ in $2.0 \%(\mathrm{~m} / \mathrm{v})$ L-cysteine.

d Based on $3 \mathrm{~s}$, without preconcentration.

e The concentration of the analyte corresponding to an absorbance of 0.0044 (in all calibration plots $0.12 \mathrm{M} \mathrm{HCl}, 1.0 \%(\mathrm{~m} / \mathrm{v}) \mathrm{NaBH}_{4}$ was used).

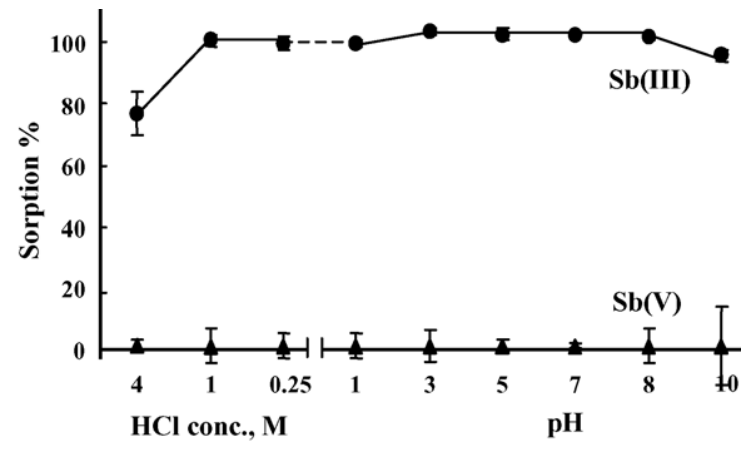

Fig. 2. Percentage uptake of Duolite GT-73 chelating resin for $\mathrm{Sb}(\mathrm{III})$ and $\mathrm{Sb}(\mathrm{V})$ as a function of $\mathrm{pH}$ and $\mathrm{HCl}$ concentration (O) $\mathrm{Sb}(\mathrm{III})$ and ( $\mathbf{\Delta}) \mathrm{Sb}(\mathrm{V})$ (5.0 $\mathrm{g} \mathrm{I}^{-1} \mathrm{Sb}$ (III), $\left.1.0 \%(\mathrm{~m} / \mathrm{v}) \mathrm{NaBH}_{4}, 0.12 \mathrm{M} \mathrm{HCl}, n=3\right)$.

reducing agents, such as potassium iodide, tartaric acid, citric acid, tartaric or citric acid mixed with potassium iodide, L-cysteine and $4 \mathrm{M} \mathrm{HCl}$ (heating at $80-100^{\circ} \mathrm{C}$ ) were examined using $40.0 \mu \mathrm{gl}^{-1} \mathrm{Sb}(\mathrm{V})$ solution. Among these, only L-cysteine offered more significant results as a pre-reducing agent and was decided to be used in the subsequent studies. Its concentration was varied between 1.0 and $5.0 \%(\mathrm{~m} / \mathrm{v})$ and $2.0 \%(\mathrm{~m} / \mathrm{v})$ was found to give the optimum results.

\subsection{Performance of Duolite GT-73 resin towards Sb(III) and $\operatorname{Sb}(V)$}

\subsubsection{Extraction efficiency as a function of $p H$}

Extraction efficiency of many of the sorbents used in speciation studies is $\mathrm{pH}$ dependent $[25,26]$. Accordingly, in the present study, the first experiments were planned to examine the sorption behavior of Duolite GT-73 resin towards $\mathrm{Sb}$ (III) and $\mathrm{Sb}(\mathrm{V})$. Duolite GT-73 has been shown to uptake several ions, such as $\mathrm{Cd}(\mathrm{II}), \mathrm{Cu}(\mathrm{II}), \mathrm{Ni}(\mathrm{II}), \mathrm{Pb}$ (II), $\mathrm{Zn}$ (II) [28] and $\mathrm{Hg}$ (II) [29] and has also been employed for the removal of arsenite [30] in previous studies. Although the sorption mechanism of Duolite GT-73 resin towards several heavy metals, namely $\mathrm{Cu}, \mathrm{Cd}, \mathrm{Ni}$, and $\mathrm{Zn}$ [31] and $\mathrm{Hg}$ [32] has been shown, no studies concerning the determination of different forms of antimony utilizing Duolite GT-73 have been found in literature. Since the present study describes the application of this resin to antimony species for the first time, it was decided to investigate the effect of $\mathrm{pH}$ on sorption as an initial experiment. For this purpose, separate standard solutions of $5.0 \mu \mathrm{g}^{-1} \mathrm{Sb}(\mathrm{III})$ and $\mathrm{Sb}(\mathrm{V})$ were prepared in various concentrations of $\mathrm{HCl}$ from 4 to $1 \mathrm{M}$ and $\mathrm{pH}$ range between 1.0 and 10.0, at constant ionic strength. The results of uptake studies are shown in Fig. 2. As seen from Fig. 2, the uptake of neither species is $\mathrm{pH}$ or acidity dependent from $1.0 \mathrm{M} \mathrm{HCl}$ almost to $\mathrm{pH} 10.0 ; \mathrm{Sb}$ (III) is taken up by Duolite GT-73 resin at all pH and acidity values mentioned above, whereas $\mathrm{Sb}(\mathrm{V})$ is not taken up at any $\mathrm{pH}$ and acidity values. This property may be considered as an important advantage, since it will possibly eliminate the $\mathrm{pH}$-adjustment step, when working with real samples. 


\subsubsection{Desorption from the resin}

Considering the $\mathrm{pH}$-uptake graphs of $\mathrm{Sb}(\mathrm{III})$ and $\mathrm{Sb}(\mathrm{V})$ species (Fig. 2), it could be said that, if the sorbed $\mathrm{Sb}$ (III) were converted to $\mathrm{Sb}(\mathrm{V})$, it would be released from the resin. Therefore, it was thought that a reagent which would oxidize $\mathrm{Sb}(\mathrm{III})$ to $\mathrm{Sb}(\mathrm{V})$ could be used as the eluent. For this purpose, several oxidants $\mathrm{K}_{2} \mathrm{Cr}_{2} \mathrm{O}_{7}, \mathrm{KIO}_{3}, \mathrm{KClO}_{3}, \mathrm{KBrO}_{3}$, $\mathrm{K}_{2} \mathrm{~S}_{2} \mathrm{O}_{8}, \mathrm{KIO}_{4}, \mathrm{HNO}_{3}$ were examined to elute $\mathrm{Sb}(\mathrm{III})$ at various concentrations. Among these, $0.05 \mathrm{M} \mathrm{KIO}_{3}$ in $2 \mathrm{M}$ $\mathrm{HCl}$ desorbed $\mathrm{Sb}$ from the column quantitatively. In addition, it was possible to quantify $\mathrm{Sb}$ (III) in $\mathrm{KIO}_{3}$ solution directly without the need for pre-reduction step. Therefore, it was concluded that $\mathrm{KIO}_{3}$ was able to elute the analyte in $\mathrm{Sb}$ (III) form, which seems contradictory to our initial thought. Since, there was no oxidation of the analyte (an absorbance signal was obtained directly in the eluates without a pre-reduction step), it could be such that, $\mathrm{KIO}_{3}$ was destroying the functional site on the resin possibly by oxidizing the $-\mathrm{SH}$ functional groups. This finding is also in accordance with a previous study [25]. On the other hand, this situation restricts the use of microcolumns more than once; however, since very small amount of Duolite GT-73 resin $(\sim 0.01 \mathrm{~g})$, is used in a microcolumn, the related cost is not significant. The only difference in the measurement of the eluates with $\mathrm{KIO}_{3}$, is the increase in the percentage of $\mathrm{NaBH}_{4}$ from 1.0 to $2.0 \%(\mathrm{~m} / \mathrm{v})$ due to the oxidizing capacity of $\mathrm{KIO}_{3}$.

\subsection{Performance of speciation and preconcentration steps}

As explained in Section 2, the preconcentration efficiency of Duolite GT-73 chelating resin with the proposed method was investigated with different water types. The sorption studies were performed using variable volumes from 20.0 to $200.0 \mathrm{ml}$ of the water samples including ultra pure water, tap water and sea water which were spiked with $\mathrm{Sb}$ (III) for an absolute amount of $200.0 \mathrm{ng}$. After eluting with $20.0 \mathrm{ml} \mathrm{KIO}_{3}$ in $2.0 \mathrm{M} \mathrm{HCl}$, the eluates were analyzed using SFI-HGAAS system described.

As can be seen from Table 2, the proposed methodology works efficiently for ultra pure and sea water samples with volumes of $20.0-200.0 \mathrm{ml}$ (final volume $20.0 \mathrm{ml}$ ). These results demonstrated the applicability of the method to a water sample even with a high matrix, such as sea water. When the recovery results for Urla and Gülbahçe region tap water samples (Table 2) were compared, totally different results were obtained in such a way that the method works efficiently for Gülbahçe tap water, whereas almost $0 \%$ recovery was obtained for Urla tap water. In order to clarify this, additional sorption/elution experiments were performed, whether it was due to the lower sorption efficiency of the resin towards $\mathrm{Sb}(\mathrm{III})$ in such a high matrix or the matrix had an effect on the $\mathrm{Sb}(\mathrm{III}) / \mathrm{Sb}$ (V) equilibria. To enlighten this situation, sorption experiments were repeated with Urla tap water and it was found that percent sorption of Duolite GT-73 resin de-
Table 2

Recovery results for ultra pure water, seawater, Urla tap water and Gülbahçe tap water

\begin{tabular}{lcccl}
\hline & $\begin{array}{l}\text { Sb(III) spike } \\
\left(\mu \mathrm{g}^{-1}\right)\end{array}$ & $\begin{array}{l}\text { Initial } \\
\text { volume }\end{array}$ & $\begin{array}{l}\text { Enrichment } \\
\text { factor }^{\mathrm{a}}\end{array}$ & $\begin{array}{l}\text { Recovery } \\
\%^{\mathrm{b}}\end{array}$ \\
\hline Ultra pure water & 10.0 & 20.0 & 1 & $104( \pm 8)$ \\
& 2.0 & 100.0 & 5 & $114( \pm 4)$ \\
& 1.0 & 200.0 & 10 & $109( \pm 4)$ \\
Seawater & 10.0 & 20.0 & 1 & $96( \pm 9)$ \\
& 2.0 & 100.0 & 5 & $110( \pm 3)$ \\
Urla tap water & 1.0 & 200.0 & 10 & $96( \pm 2)$ \\
& 10.0 & 20.0 & 1 & $<2$ \\
& 2.0 & 100.0 & 5 & $<2$ \\
Gülbahçe tap water & 10.0 & 200.0 & 10 & $<2$ \\
& 2.0 & 20.0 & 1 & $118( \pm 7)$ \\
& 1.0 & 100.0 & 5 & $101( \pm 10)$ \\
& 200.0 & 10 & $85( \pm 13)$ \\
\hline
\end{tabular}

$2.0 \%(\mathrm{~m} / \mathrm{v}) \mathrm{NaBH}_{4}, 0.12 \mathrm{M} \mathrm{HCl}$.

a Final volume: $20.0 \mathrm{ml}$

b $n=3$.

creased below $20 \%$ for $\mathrm{Sb}$ (III). An additional experiment was performed using L-cysteine to be sure that antimony species were in +3 oxidation state. The quantitative spike recoveries obtained (Table 3), confirmed that the hard matrix of Urla tap water has a strong effect on $\mathrm{Sb}(\mathrm{III}) / \mathrm{Sb}(\mathrm{V})$ equilibria (possibly oxidizing $\mathrm{Sb}$ (III) to $\mathrm{Sb}(\mathrm{V})$ ). This finding also indicates the importance of the pre-reduction step prior to the application of the proposed methodology.

\subsection{Method validation}

\subsubsection{Recoveries with $S b(I I I)$ and $S b(V)$}

The efficiency of the proposed method for $\mathrm{Sb}$ (III) and $\mathrm{Sb}(\mathrm{V})$ with and without pre-reduction step was checked with microcolumns. Aliquots of sample were spiked with $20.0 \mu \mathrm{g}^{-1} \mathrm{Sb}(\mathrm{III})$ and $\mathrm{Sb}(\mathrm{V})$ separately and applied to microcolumns of Duolite GT-73 resin. Each microcolumn was then washed with de-ionized water and eluted with $0.05 \mathrm{M}$ $\mathrm{KIO}_{3}$ in $2 \mathrm{M} \mathrm{HCl}$. Blank solution and the calibration standards were prepared using the same procedure for matrixmatching, as explained in Section 2. The concentration of $\mathrm{Sb}$ (III) in the eluates was determined by SFI-HGAAS and the percent recovery in each sample was calculated. The re-

Table 3

Recovery results for seawater, Gülbahçe and Urla tap water

\begin{tabular}{lll}
\hline & $\begin{array}{l}20.0 \mathrm{ml}^{\mathrm{a}, \mathrm{b}} \\
(\text { no preconcentration) }\end{array}$ & $\begin{array}{l}100.0 \mathrm{ml}^{\mathrm{a}, \mathrm{b}}(5 \text { times } \\
\text { preconcentration })\end{array}$ \\
\hline Seawater & $101( \pm 2)$ & $107( \pm 1)$ \\
Gülbahçe tap water & $100( \pm 7)$ & $108( \pm 2)$ \\
Urla tap water & $109( \pm 4)$ & $108( \pm 2)$
\end{tabular}

$2.0 \%(\mathrm{~m} / \mathrm{v}) \mathrm{NaBH}_{4}, 0.12 \mathrm{M} \mathrm{HCl}, 2.0 \%(\mathrm{~m} / \mathrm{v})$ L-cysteine was used as the pre-reductant.

a Final volume: $20.0 \mathrm{ml}$.

b $n=3$. 
Table 4

Spike recovery results for $\mathrm{Sb}(\mathrm{III})$ and $\mathrm{Sb}(\mathrm{V})$ with ultra pure water.

\begin{tabular}{|c|c|c|c|c|c|}
\hline Experiment number & $\mathrm{Sb}(\mathrm{III})\left(\mu \mathrm{g} \mathrm{l}^{-1}\right)$ & $\mathrm{Sb}(\mathrm{V})\left(\mu \mathrm{g} \mathrm{l^{-1 }}\right)$ & Pre-reduction step & $\mathrm{Sb}$ found $\left(\mu \mathrm{g} \mathrm{1^{-1 }}\right)$ & Recovery $\%^{\mathrm{a}, \mathrm{b}}$ \\
\hline 1 & 20.0 & - & No & $19.8( \pm 0.7)$ & $99( \pm 4)$ \\
\hline 2 & 20.0 & - & Yes & $20.1( \pm 0.9)$ & $100( \pm 5)$ \\
\hline 3 & - & 20.0 & No & $<\mathrm{LOD}$ & $<2$ \\
\hline 4 & - & 20.0 & Yes & $20.4( \pm 0.2)$ & $102( \pm 1)$ \\
\hline 5 & 20.0 & 20.0 & No & $20.8( \pm 0.1)$ & $104( \pm 1)$ \\
\hline 6 & 20.0 & 20.0 & Yes & $40.7( \pm 0.8)$ & $102( \pm 2)$ \\
\hline
\end{tabular}

$2.0 \%(\mathrm{~m} / \mathrm{v}) \mathrm{NaBH}_{4}, 0.12 \mathrm{M} \mathrm{HCl}, 2.0 \%(\mathrm{~m} / \mathrm{v})$ L-cysteine was used as the pre-reductant.

${ }^{\text {a }}$ Sample/eluent volumes: $20.0 \mathrm{ml}$.

b $n=3$.

sults given in Table 4, are efficient for $\mathrm{Sb}(\mathrm{III})$ with/without $\mathrm{L}$-cysteine pre-reduction and for $\mathrm{Sb}(\mathrm{V})$ with $\mathrm{L}$-cysteine prereduction.

As seen from Table 4, when only $\mathrm{Sb}$ (III) is present, it can be determined with or without the pre-reduction steps (Exp. no. 1 and 2). When $\mathrm{Sb}(\mathrm{V})$ is present, it can be determined only after a pre-reduction step $(2.0 \%(\mathrm{~m} / \mathrm{v}) \mathrm{L}$-cysteine) (Exp. no. 3 and 4). Another important feature of the study is that interference-free determination of $\mathrm{Sb}$ (III) is possible in the presence of $\mathrm{Sb}(\mathrm{V})$ where total inorganic $\mathrm{Sb}$ could be determined after the pre-reduction step (Exp. no. 5 and 6).

\subsubsection{Analysis of a standard reference material}

In addition to the spike recovery tests mentioned above, the performance of the method was realized through the analysis of a standard reference material (SRM from NIST, Cat. No. 1640). For this purpose, $10.0 \mathrm{ml}$ aliquots of SRM were taken and processed by the proposed method, loading onto the Duolite GT-73 microcolumn and elution with $\mathrm{KIO}_{3} / \mathrm{HCl}$ mixture. The eluates were analyzed by SFI-HGAAS, and Sb(III) concentrations were determined from the matrix-matched calibration plot. In addition, the SRM solution was analyzed also with SFI-HGAAS system directly after acidification (Table 5). The results are in accordance with the certified value. These results may be evaluated in such a way that, there is no need to apply the Duolite GT-73 microcolumn method for such situations. However, it must be considered that the SRM used does not contain a high matrix and can be considered as a "clean" solution for SFI-HGAAS to be applied directly. The efficiency of the method must have been checked with a more difficult matrix in which direct
Table 5

Analysis of SRM solution

\begin{tabular}{llll}
\hline & $\begin{array}{l}\text { Certified value } \\
\left(\mu \mathrm{g}^{-1}\right)\end{array}$ & $\begin{array}{l}\text { Found } \\
\left(\mu \mathrm{g}^{-1}\right)\end{array}$ & $\begin{array}{l}\text { Recovery } \\
\%^{\mathrm{a}}\end{array}$ \\
\hline $\begin{array}{l}\text { Direct determination } \\
\text { by SFI-HGAAS }\end{array}$ & $13.79( \pm 0.42)$ & 13.1 & 95 \\
$\begin{array}{l}\text { Proposed } \\
\text { methodology }\end{array}$ & $13.79( \pm 0.42)$ & $13.3( \pm 1.1)$ & $96( \pm 8)^{\mathrm{b}}$ \\
\hline $\begin{array}{l}2.0 \%(\mathrm{~m} / \mathrm{v}) \mathrm{NaBH}_{4}, 0.12 \mathrm{M} \mathrm{HCl}, 2.0 \%(\mathrm{~m} / \mathrm{v}) \\
\text { pre-reductant. }\end{array}$ \\
$\begin{array}{l}\text { a } \text { Lample/eluent volumes: } 10.0 \mathrm{ml} . \\
\text { b } n=3 .\end{array}$
\end{tabular}

determination of $\mathrm{Sb}$ was not feasible. Therefore, in the subsequent experiment, $20.0 \mathrm{ml}$ of seawater, a possible heavymatrix sample, was spiked with $20.0 \mu \mathrm{g} 1^{-1} \mathrm{Sb}$ (III) and then analyzed with SFI-HGAAS (Exp. no. 1 in Table 6). As can be seen, antimony could not be determined in seawater directly, which indicates the effect of matrix on the performance of SFI-HGAAS system. On the other hand, the succeeding experiments (Exp. nos. 2-5) demonstrated the capability of the proposed methodology in removing the heavy matrix and allowing the determination of both $\mathrm{Sb}(\mathrm{III})$ and $\mathrm{Sb}(\mathrm{V})$ in seawater. In experiment number 4 , the percent sorption value was given in a range $0-50$, because it was not possible to obtain a reproducible result with $\mathrm{Sb}(\mathrm{V})$.

After the efficiency of the method was verified through spike recovery tests and via the analysis of SRM, several bottled drinking water samples were analyzed for Sb determination and they were found to contain no $\mathrm{Sb}$ above the permissible level. The concentrations were below the limit of quantification $\left(<0.30 \mu \mathrm{g} \mathrm{l}^{-1}\right)$.

Table 6

Spike recovery results for $\mathrm{Sb}(\mathrm{III})$ and $\mathrm{Sb}(\mathrm{V})$ with sea water

\begin{tabular}{lllllll}
\hline Exp. no. & $\mathrm{Sb}(\mathrm{III})\left(\mu \mathrm{g} l^{-1}\right)$ & $\mathrm{Sb}(\mathrm{V})\left(\left.\mu \mathrm{g}\right|^{-1}\right)$ & Pre-reduction & Microcolumn pre-treatment & Sorption $\%$ & Recovery $\%^{\mathrm{a}, \mathrm{b}}$ \\
\hline 1 & 20.0 & - & No & No & Not applicable & 0 \\
2 & 20.0 & - & No & Yes & $92( \pm 10)$ & $91( \pm 4)$ \\
3 & 20.0 & - & Yes & Yes & $100( \pm 3)$ & $96( \pm 2)$ \\
4 & - & 20.0 & No & Yes & $0-50$ & 0 \\
5 & - & 20.0 & Yes & Yes & $96( \pm 4)$ & $111( \pm 3)$ \\
\hline
\end{tabular}

$2.0 \%(\mathrm{~m} / \mathrm{v}) \mathrm{NaBH}_{4}, 0.12 \mathrm{M} \mathrm{HCl}, 2.0 \%(\mathrm{~m} / \mathrm{v}) \mathrm{L}$-cysteine was used as the pre-reductant.

a Sample/eluent volumes: $20.0 \mathrm{ml}$.

${ }^{\mathrm{b}} n=3$. 


\section{Conclusion}

It has been shown that Duolite GT-73 resin with its - SH functional groups can be employed for the selective sorption of inorganic $\mathrm{Sb}$ (III) from the water. The advantage of Duolite GT-73 resin in terms of Sb speciation is that, it eliminates the need for $\mathrm{pH}$ adjustment step since only $\mathrm{Sb}(\mathrm{III})$ is retained on the column at all $\mathrm{pH}$ and acidity values tested. If $\mathrm{Sb}(\mathrm{V})$ is to be determined (the predominant form of Sb in many types of oxidizing waters), a pre-reduction step with $\mathrm{L}$-cysteine must be applied.

Another possibility that Duolite GT-73 microcolumn can provide is its suitability for field use. This property may eliminate the transportation of possibly high volumes of samples to the laboratory by enabling the sampling to be realized in situ with low volumes.

In addition, the practical feature of Duolite GT-73 microcolumn makes its combination with other techniques possible. For example, with the proposed methodology, ICP-MS may offer higher preconcentration factors with even smaller volumes. More importantly, the method has the advantage of matrix removal capability which may have crucial importance in the analysis of high dissolved solids samples using ICP-MS.

\section{Acknowledgement}

We would like to acknowledge İzmir Institute of Technology for support of this work through the fund 2001 FENYL 14.

\section{References}

[1] M. Fiella, N. Belzile, Y.W. Chen, Earth-Sci. Rev. 59 (2002) 265.

[2] M. Fiella, N. Belzile, Y.W. Chen, Earth-Sci. Rev. 57 (2002) 125.

[3] M.J. Nash, J.E. Maskall, S.J. Hill, J. Environ. Monit. 2 (2000) 97.

[4] M. Krachler, H. Emons, J. Zheng, Trends Anal. Chem. 20 (2001) 79 .

[5] K. Bencze, Handbook on Metals in Clinical and Analytical Chemistry, Marcel Dekker, New York, 1994, pp. 227-236.
[6] United States Environmental Protection Agency, USEPA, 1 (1979). EP-440/4-79-029A.

[7] Council of the European Communities, Official Journal L, 129 (1976) 23.

[8] United States Environmental Protection Agency, USEPA (1999). Doc. 810-F-94-001.

[9] Council of the European Union, Official Journal L, 330 (1998) 32.

[10] N. Ozdemir, M. Soylak, L. Elci, M. Dogan, Anal. Chim. Acta 505 (2004) 37.

[11] M. Yu, G. Liu, Talanta 30 (1983) 265.

[12] Y.C. Sun, J.Y. Yang, Anal. Chim. Acta 395 (1999) 293.

[13] S. Garbos, E. Bulska, A. Hulanicki, Z. Fijalek, K. Soltyk, Spectrochim. Acta B 55 (2000) 793.

[14] T. Kubota, A. Kawakami, T. Sagara, N. Ookubo, T. Okutani, Talanta 53 (2001) 1117.

[15] M.B. De la Calle Guntinas, C. Camara, Y. Madrid, Anal. Chim. Acta 252 (1991) 161.

[16] S. Garbos, E. Bulska, A. Hulanicki, N.I. Shcherbinina, E.M. Sedykh, Anal. Chim. Acta 342 (1997) 167.

[17] S. Han-Wen, S. Xiao-Quan, N. Zhe-Ming, Talanta 29 (1982) 589.

[18] J. Dedina, D.L. Tsalev, Hydride Generation Atomic Absorption Spectrometry, Wiley, Chichester, 1995.

[19] B. Welz, M. Sperling, Atomic Absorption Spectrometry, 3rd ed., Wiley, Weinheim, 1999.

[20] C.A. León, M. Montes-Bayón, J.A. Caruso, J. Chromatogr. A 974 (2002) 1.

[21] P. Montesinos, M.L. Cervera, A. Pastor, M. Guardia, Talanta 60 (2003) 787

[22] S. Sato, Talanta 32 (1985) 341.

[23] M. Krachler, M. Burow, H. Emons, Analyst 124 (1999) 777.

[24] G. Göktürk, M. Delzendeh, M. Volkan, Spectrochim. Acta B 55 (2000) 1061

[25] A. Körez, A.E. Eroğlu, M. Volkan, O.Y. Ataman, J. Anal. Atom. Spectrom. 15 (2000) 1599.

[26] F. Sahin, M. Volkan, A.G. Howard, O.Y. Ataman, Talanta 60 (2003) 1003.

[27] Z.B. Alfassi, C.M. Wai, Preconcentration Techniques for Trace Elements, CRC Press Inc., Florida, 1992.

[28] T. Vaughan, C.W. Seo, W.E. Marshall, Bioresource Technol. 78 (2001) 133

[29] A. Dabrowski, Z. Hubicki, P. Podkoscielny, E. Robens, Chemosphere 56 (2004) 91

[30] L. Dominguez, Z. Yue, J. Economy, C.L. Mangun, React. Funct. Polym. 53 (2002) 205.

[31] B. Saha, M. Iglesias, I.W. Cumming, M. Streat, Solvent Extr. Ion Exc. 18 (2000) 133

[32] S. Chiarle, M. Ratto, M. Rovatti, Water Res. 34 (2000) 2971. 